This item was submitted to Loughborough's Research Repository by the author.

Items in Figshare are protected by copyright, with all rights reserved, unless otherwise indicated.

\title{
Antecedents of perceived coach interpersonal behaviors: the coaching environment and coach psychological well- and ill-being
}

PLEASE CITE THE PUBLISHED VERSION

http://journals.humankinetics.com/jsep

\section{PUBLISHER}

(c) Human Kinetics, Inc.

\section{VERSION}

VoR (Version of Record)

\section{LICENCE}

CC BY-NC-ND 4.0

\section{REPOSITORY RECORD}

Stebbings, Juliette, lan M. Taylor, Christopher M. Spray, and Nikos Ntoumanis. 2019. "Antecedents of Perceived Coach Interpersonal Behaviors: The Coaching Environment and Coach Psychological Well- and IIIbeing". figshare. https://hdl.handle.net/2134/10618. 
This item was submitted to Loughborough's Institutional Repository (https://dspace.lboro.ac.uk/) by the author and is made available under the following Creative Commons Licence conditions.

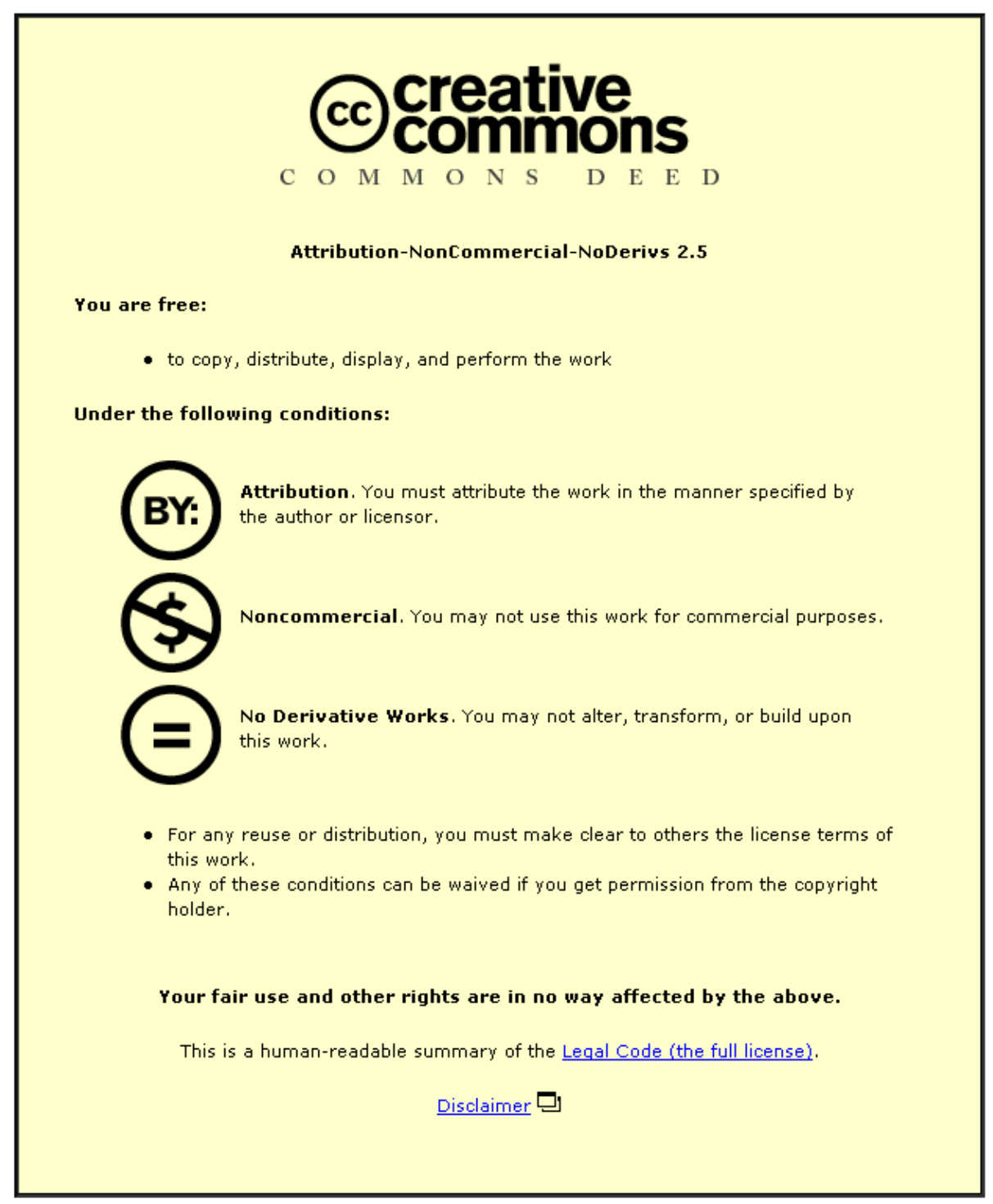

For the full text of this licence, please go to: http://creativecommons.org/licenses/by-nc-nd/2.5/ 


\title{
Antecedents of Perceived Coach Interpersonal Behaviors: The Coaching Environment and Coach Psychological Well- and III-Being
}

\author{
Juliette Stebbings, ${ }^{1}$ lan M. Taylor, ${ }^{1}$ \\ Christopher M. Spray, ${ }^{1}$ and Nikos Ntoumanis ${ }^{2}$ \\ ${ }^{1}$ Loughborough University; ${ }^{2}$ University of Birmingham
}

\begin{abstract}
Embedded in the self-determination theory (Deci \& Ryan, 2000) framework, we obtained self-report data from 418 paid and voluntary coaches from a variety of sports and competitive levels with the aim of exploring potential antecedents of coaches' perceived autonomy supportive and controlling behaviors. Controlling for socially desirable responses, structural equation modeling revealed that greater job security and opportunities for professional development, and lower work-life conflict were associated with psychological need satisfaction, which, in turn, was related to an adaptive process of psychological well-being and perceived autonomy support toward athletes. In contrast, higher work-life conflict and fewer opportunities for development were associated with a distinct maladaptive process of thwarted psychological needs, psychological ill-being, and perceived controlling interpersonal behavior. The results highlight how the coaching context may impact upon coaches' psychological health and their interpersonal behavior toward athletes. Moreover, evidence is provided for the independence of adaptive and maladaptive processes within the self-determination theory paradigm.
\end{abstract}

Keywords: job pressures, occupational health, affect, vitality, emotional and physical exhaustion

The sports coach occupies a central and influential role in the youth sport environment and may affect the quality of an athlete's sport experience through the interpersonal interactions that occur (Amorose, 2007). Athlete-based correlates of coaching behavior have been the focus of considerable research, some of which has used self-determination theory (SDT; Deci \& Ryan, 2000) as a guiding framework. Self-determination theory distinguishes between autonomy supportive and controlling interpersonal styles. An autonomy supportive environment is created when coaches acknowledge their athletes' feelings and perspectives, and provide

Juliette Stebbings, Ian M. Taylor, and Christopher M. Spray are with the School of Sport, Exercise and Health Sciences, Loughborough University, Leicestershire, U.K. Nikos Ntoumanis is with the School of Sport and Exercise Science, University of Birmingham, Edgbaston, Birmingham, U.K. 
athletes with opportunities for input and decision making (Mageau \& Vallerand, 2003). Contrastingly, a controlling environment is created when coaches intimidate athletes through verbal abuse and punishment, issue criticism and task-contingent rewards, and pressure athletes into thinking and behaving in certain ways (Bartholomew, Ntoumanis, \& Thøgersen-Ntoumani, 2010). Although debated in the wider literature (cf. Soenens, Vansteenkiste, \& Sierens, 2009, who suggested that parent promotion of volitional functioning stands in opposition to parental control), sport-based research has found autonomy supportive and controlling coaching styles to be relatively independent (e.g., Pelletier, Fortier, Vallerand, \& Brière, 2001). That is, coaches can engage in autonomy supportive and controlling strategies simultaneously, or create an environment that is neither autonomy supportive nor controlling (e.g., a neutral style; Bartholomew et al., 2010). Research is therefore required to examine these interpersonal styles concurrently.

A wealth of SDT-based research has documented many beneficial effects of autonomy supportive coaches, as well as deleterious effects of controlling coaches. For instance, athletes who perceive their coach to be autonomy supportive may benefit from enhanced psychological well-being and self-determined motivation (see Amorose, 2007, for a review). Consequences for athletes who perceive their coach as controlling, however, include poor quality motivation and increased likelihood of dropping out (Pelletier et al., 2001).

This evidence suggests that an autonomy supportive coaching style should be promoted and controlling coaching styles diminished; however, scant research addresses potential reasons why coaches employ these contrasting interpersonal styles. Such attention is necessary so that interventions aimed at manipulating coach behavior can target these antecedents. The present study aimed to achieve this by testing a theoretically informed model of potential antecedents of perceived coach interpersonal behavior. Specifically, we examined whether coaches' perceptions of their working environment were associated with their perceived provision of autonomy support or control toward their athletes. Further, we examined coaches' fundamental psychological need fulfillment and frustration, and well- and ill-being as potentially distinct mechanisms that may explain these relationships.

\section{The Social Context and Basic Psychological Needs}

A major tenet of SDT is that in order for humans to develop and function optimally, the social context must support their basic psychological needs for competence, autonomy, and relatedness. The need for competence is satisfied when individuals perceive a sense of mastery through effectively interacting with their environment and demonstrating their capabilities. The need for autonomy refers to the desire to feel volitional in the regulation of one's behavior. Last, the need for relatedness concerns the desire to experience a sense of belonging and connection with significant others (Deci \& Ryan, 2000). Advocates of SDT suggest that certain social-contextual conditions have the potential to fulfill an individual's basic psychological needs, whereas other conditions may actively undermine their psychological needs (Deci \& Ryan, 2000). This proposal is also supported by empirical research. For example, Taylor, Ntoumanis, and Standage (2008) reported that perceived job pressures and perceptions of students' motivation were related to physical education teachers' psychological need satisfaction. Similarly, athletes' 
psychological needs have been shown to be explicitly thwarted when coaches create a pressurized and controlling training environment (Bartholomew, Ntoumanis, Ryan, Bosch, \& Thøgersen-Ntoumani, 2011). However, scarce research in sport settings has investigated how elements of the coaching context may contribute to the satisfaction or thwarting of coaches' psychological needs. We aimed to fill this void by exploring three salient contextual factors that have the potential to impact upon coaches' psychological needs.

In accordance with Schaufeli and Bakker's (2004) job demands-resources model (JD-R model), we aimed to investigate both the favorable (i.e., resources) and unfavorable (i.e., demands) elements of the work context. Job resources refer to aspects of a job that stimulate personal growth and development, and have been shown to be associated with psychological need satisfaction (Van den Broeck, Vansteenkiste, De Witte, \& Lens, 2008). As such, we sought to investigate coaches' opportunities for professional development as a job resource. In an interview study with high performance coaches, Allen and Shaw (2009) highlighted that the existence of formalized coaching accreditation pathways, training courses, and informal mentoring initiatives may support coaches' psychological needs and allow them to thrive. Conversely, coaches who experienced a lack of these opportunities felt that their needs were frustrated, and that they were not able to develop professionally. These findings suggest that opportunities for professional development (or lack thereof) have the potential to satisfy (or thwart) coaches' psychological needs.

Job security has also been highlighted as a job resource (Bakker \& Demerouti, 2007), and the beneficial effects of job security on employees' psychological health have been demonstrated (e.g., Probst, 2003). On the other hand, low job security has been highlighted in the sport literature as a significant source of stress for coaches (Olusoga, Butt, Hays, \& Maynard, 2009). Adopting a SDT perspective, psychological need satisfaction and thwarting may mediate these relationships.

Contrastingly, job demands are defined within the JD-R model as those aspects of the work context that tax employees' personal capacities and are, therefore, associated with detriments in psychological health. Work-life conflict may be such a demand, as it has also been cited as a significant strain on coaches (Olusoga et al., 2009). In the organizational psychology literature, work-family conflict has been positively related to depression (Major, Klein, \& Ehrhart, 2002) and workhome interference, as part of a composite factor measuring job demands, has been negatively linked to psychological need satisfaction in a sample of work employees (Van den Broeck et al., 2008).

Despite our speculations that these contextual factors may satisfy or thwart coaches' psychological needs, these relationships have yet to be formally tested. Filling this gap may provide insight into the social-contextual conditions that are required for coaches to thrive within sport.

\section{Basic Psychological Needs and Psychological Well- and III-Being}

Basic psychological needs theory (BPNT; Deci \& Ryan, 2000), a subtheory of the wider SDT framework, considers the fulfillment of competence, autonomy, and relatedness to be essential in the development and maintenance of psychological 
well-being. From the SDT point of view, psychological well-being is often conceptualized as the experience of pleasure and happiness (i.e., positive affect), in conjunction with a state of positive, internal energy known as subjective vitality (Ryan \& Frederick, 1997). Research in the sporting domain, including a sample of sports coaches, has demonstrated a positive relationship between psychological need satisfaction and indices of psychological well-being at both the daily and general levels (e.g., Gagné, Ryan, \& Bargmann, 2003; Stebbings, Taylor, \& Spray, 2011). In contrast, the undermining effects of psychological need thwarting will result in costs for psychological health (Deci \& Ryan, 2000). However, psychological ill-being is not merely reflected in the absence of positive affect or vitality, but in the presence of negative affect and explicit psychological malfunction, such as emotional and physical exhaustion (Maslach \& Leiter, 1997; Watson, Tellegen, \& Clark, 1988). Thus, psychological well-being and ill-being represent distinct concepts.

Despite the hypothesis that need thwarting is associated with psychological malfunction, links between low need satisfaction and indices of ill-being have been unsubstantiated in several instances (e.g., Gagné et al., 2003; Quested \& Duda, 2010). Recent conceptual advancements that define psychological need thwarting as conceptually distinct from low need satisfaction may explain this lack of significant association. Specifically, low need satisfaction is posited to reflect an individual's dissatisfaction with the extent to which their needs are being met (e.g., a person struggles to develop meaningful relationships with his or her teammates), whereas need thwarting reflects the overt frustration of an individual's needs (e.g., a person feels actively rejected by his or her teammates; Bartholomew, Ntoumanis, Ryan, \& Thøgersen-Ntoumani, 2011). Weak negative correlations between need thwarting and need satisfaction subscales (between $r=-.21$ and -.27) as well as exploratory factor analyses support the contention that need thwarting and need satisfaction represent different concepts (Bartholomew, Ntoumanis, Ryan, \& Thøgersen-Ntoumani, 2011). Psychological need thwarting has been shown to be more strongly associated with psychological ill-being at both the general and daily levels, compared with low psychological need satisfaction (Bartholomew, Ntoumanis, Ryan, Bosch, et al., 2011).

Overall, the independence of need satisfaction and thwarting, combined with the independence of psychological well-being and ill-being, suggests that two distinct processes may exist. On the one hand, satisfaction of individuals' psychological needs may lead to enhanced psychological health and optimal functioning. In contrast, ill-being and psychological malfunction are likely to occur if one's needs are explicitly thwarted.

\section{Psychological Well- and III-Being and Interpersonal Behavior}

A substantial body of evidence details the links between a positive affective and energized state and numerous interpersonal behaviors, including spontaneous interactions with others, helping and altruism, bargaining, negotiating, persuasive communication, and positive teaching behaviors in classroom settings (see Forgas, 2002, for a review; Klusmann, Kunter, Trautwein, Lüdtke, \& Baumert, 2008). Coaching-based work by Stebbings et al. (2011) demonstrated a strong positive 
relationship between a coach's sense of psychological well-being and perceived autonomy supportive coaching style, yet a much weaker, negative relationship between psychological well-being and their perceived use of a controlling interpersonal style. This suggests that other constructs may be more salient than wellbeing in predicting controlling behavior, and the differentiation between well- and ill-being detailed above may help in solving this issue.

Within the healthcare context, evidence exists that physicians' experience of burnout impaired the quality of interactions with their patients, including less understanding of the individual needs of patients, and being less courteous, caring, and attentive to patients, compared with physicians with low levels of burnout (Shirom, Nirel, \& Vinokur, 2006). Similarly, teachers' emotional exhaustion has been associated with their use of psychologically controlling teaching strategies (Soenens, Sierens, Vansteenkiste, Dochy \& Goossens, 2012). In light of this evidence, it is possible that a coach's controlling interpersonal style is better predicted by psychological ill-being, compared with well-being; however, research has yet to explicitly test this relationship in any domain.

\section{Summary and Hypotheses}

A considerable amount of SDT-based research has explored how coaches' interpersonal behavior can influence athletes' psychological experiences in sport; however, scant research has considered potential antecedents of coaches' interpersonal style, particularly with regards to the coaching environment. As an exception, Stebbings and colleagues (2011) found that coaches' autonomy and competence need satisfaction was related to their psychological well-being, which, in turn predicted their perceived interpersonal behavior toward their athletes. The present study extends this work in several ways. First, we investigated how elements of the coaching context can satisfy versus frustrate coaches' basic psychological needs. Second, the current study examines whether autonomy supportive and controlling interpersonal styles have distinct antecedents, by examining both psychological need satisfaction and thwarting, and psychological well- and ill-being, concurrently. Last, the present research proposes that when coaches function within an adaptive environment, this will indirectly lead coaches to create a healthy interpersonal climate for their athletes - a process that has yet to be addressed.

We hypothesized that greater perceived opportunities for professional development and job security, as well as lower work-life conflict, would be associated with higher psychological need satisfaction and lower psychological need thwarting. Second, based upon BPNT-based research (e.g., Bartholomew, Ntoumanis, Ryan, Bosch, et al., 2011; Stebbings et al., 2011), it was hypothesized that following these antecedents, two distinct processes would ensue. We proposed that coaches' psychological need satisfaction would positively predict their psychological wellbeing, whereas psychological need thwarting would positively predict their psychological ill-being. In line with Bartholomew and colleagues, we also predicted that psychological need satisfaction and need thwarting would be correlated. In turn, psychological well-being was proposed to positively predict coaches' perceptions of their autonomy support toward their athletes, whereas psychological ill-being was hypothesized to positively predict perceptions of their controlling behavior. 
Existing research has demonstrated a moderate negative correlation between coach autonomy supportive and controlling behavior (Stebbings et al., 2011); hence, we hypothesized a similar relationship. We also included a measure of social desirability to control for coaches' tendency to respond to items about their behaviors toward others in a socially desirable manner.

To fully explore the processes outlined in our hypothesized model, we also examined the indirect relationships between the social-contextual factors and perceived coaching styles. As such, we aimed to offer initial, cross-sectional substantiation that creating an adaptive environment for coaches (in which they can enjoy a sense of job security, opportunities for professional development, and a stable work-life balance) may lead coaches to create an adaptive interpersonal environment for their athletes because they psychologically thrive. Last, consistent with recommendations by Stebbings et al. (2011), we examined the invariance of the proposed model across competitive level.

\section{Method}

\section{Participants and Procedures}

Following approval from a university ethics committee, the study was conducted according to APA guidelines. Coaches who consented to participate responded to a multisection online questionnaire that took approximately $25 \mathrm{~min}$ to complete. The sample comprised 418 coaches (306 male, 112 female; $M_{\text {age }}=43.68$ years, $S D$ $=14.41$, range $=18-78$ years $)$, recruited via national governing bodies and sports club websites. Coaches were involved at the recreational $(n=66)$, club $(n=187)$, county $(n=86)$, national $(n=51)$, and international/professional $(n=28)$ levels, and represented one of 32 sports. Coaches had, on average, $13.60(S D=10.79)$ years of coaching experience, and spent $10.14(S D=10.68)$ hours per week coaching. Coaches reported their job status as either paid in a full-time role $(n=60)$, paid in a part-time role $(n=132)$, full-time volunteer $(n=12)$, part-time volunteer $(n=$ 173 ), or other (a combination of paid and voluntary work, $n=41$ ).

\section{Measures}

The Coaching Context. Due to the lack of existing measures that assess the relevant contextual factors within coaching settings, a 12-item scale was compiled for the purpose of this study following a review of the coaching and organizational literature. Four items were created to assess opportunities for professional development based on the types of opportunities that have been reported as pertinent to sport coaches (Allen \& Shaw, 2009; e.g., "I am provided with ongoing training in coaching techniques"). Job security was assessed using the two-item job security subscale of Chelladurai and Ogasawara's (2003) Coach Satisfaction Questionnaire, which was supplemented with two additional created items (e.g., "I am satisfied with my job security"). Four items assessing work-life conflict were adapted from the Work-Family Conflict Scale (Netemeyer, Boles, \& McMurrian, 1996) to reflect general sources of conflict, as opposed to referring to those pertaining to the family, specifically (e.g., "The demands of coaching interfere with my other roles in life"). Participants were asked to reflect on their 
coaching environment over the last month, and rate the extent to which each statement was true on a seven-point scale anchored by 1 (not at all true) and 7 (very true).

Psychological Need Satisfaction. Satisfaction of competence, autonomy, and relatedness was measured using the Basic Need Satisfaction at Work Scale (BNSAW; Deci et al., 2001) adapted to the coaching context. In line with modifications suggested by Ntoumanis (2005), only the 12 positively worded items were used. Competence was assessed using three items (e.g., "I have been able to learn interesting new skills through coaching"), autonomy was assessed using four items (e.g., "I feel like I can make a lot of inputs into deciding how my coaching gets done"), and relatedness was assessed using five items (e.g., "People I interact with in my coaching role care about me"). Coaches were asked to consider their coaching experiences over the last month and rate the extent to which they agreed with each of the statements on a scale ranging from 1 (strongly disagree) to 7 (strongly agree). Previous research has found the positively worded BNSAW items to possess adequate factorial validity and internal consistency in a sample of secondary school students (Ntoumanis, 2005).

Psychological Need Thwarting. The 12-item Psychological Need Thwarting Scale (PNTS; Bartholomew, Ntoumanis, Ryan, \& Thøgersen-Ntoumani, 2011) was adapted to the coaching context to measure the thwarting of coaches' psychological needs. Competence, autonomy, and relatedness were each assessed using four items, for example, "In my coaching role, there are times when I am told things that make me feel incompetent," "I feel pushed to coach in certain ways," and "In my coaching role, I feel rejected by those around me," respectively. Coaches were asked to rate the extent to which they agreed with each of the statements for their coaching experiences over the last month, on a scale ranging from 1 (strongly disagree) to 7 (strongly agree). Bartholomew and coworkers reported good internal reliability, factorial validity, and predictive validity in a sample of adolescent athletes.

Psychological Well-Being. Items assessing coaches' positive affect and subjective vitality were used to measure coaches' psychological well-being. Positive affect was measured using the 10-item positive affect subscale from the Positive and Negative Affect Scale (PANAS; Watson et al., 1988). Coaches indicated the extent to which they had experienced positive emotions (e.g., "excited," "determined," and "enthusiastic") while coaching during the last month on a five-point scale ranging from 1 (not at all or very slightly) to 5 (extremely). Watson et al. (1988) reported acceptable factorial validity and internal consistency of the subscale.

Coaches' subjective vitality was measured using the seven-item Subjective Vitality Scale (Ryan \& Frederick, 1997), which assessed the degree to which participants felt psychologically vigorous and energized while coaching during the last month. Items were preceded by the stem, "When I am coaching . .." (e.g., "When I am coaching, I nearly always feel alert and awake"), and required coaches to rate their experiences on a seven-point scale ranging from 1 (not at all true) to 7 (very true). Ryan \& Frederick (1997) found the scale to have good internal consistency and factorial structure. 
Psychological III-Being. Items assessing coaches' negative affect and emotional and physical exhaustion were used to measure coaches' psychological ill-being. Negative affect was measured using the 10 -item negative affect subscale from the PANAS. Coaches indicated the extent to which they had experienced negative emotions (e.g., "distressed," "irritable," and "upset") while coaching during the last month, on a five-point scale ranging from 1 (not at all or very slightly) to 5 (extremely). Watson et al. (1988) reported acceptable factorial validity and internal consistency of the subscale.

Coaches' emotional and physical exhaustion was assessed using the respective five-item subscale of the Athlete Burnout Questionnaire (ABQ; Raedeke \& Smith, 2001), adapted to the coaching context. Coaches were asked to rate the extent to which they had experienced each of the statements (e.g., "I am exhausted by the mental and physical demands of coaching") over the past month, on a five-point scale ranging from 1 (almost never) to 5 (almost always). Raedeke and Smith (2001) reported that the subscale possesses adequate factorial structure and internal reliability.

Coach Autonomy Supportive Style. The six-item version of the Health Care Climate Questionnaire (HCCQ; Williams, Grow, Freedman, Ryan, \& Deci, 1996) adapted to the sport context was used to assess coaches' perceptions of their autonomy supportive behavior. Coaches were asked to reflect on their coaching practices over the last month and rate the extent to which they agreed with each of the items (e.g., "I encourage my athletes to ask questions") on a seven-point scale anchored by 1 (strongly disagree) and 7 (strongly agree). Previous research has similarly adapted the HCCQ items and found them to have acceptable internal consistency and factorial validity (Stebbings et al., 2011).

Coach Controlling Style. Coaches' perceptions of their controlling interpersonal style were assessed using the 15-item Controlling Coach Behaviors Scale (CCBS; Bartholomew et al., 2010), which was modified to reflect a coach's perspective. The measure assesses four types of controlling behaviors, including coaches' controlling use of rewards (e.g., "I only reward/praise my athlete(s) to make them train harder"), negative conditional regard (e.g., "I pay my athletes less attention if they displease me"), intimidation (e.g., "I embarrass my athletes in front of others if they do not do certain things"), and excessive personal control (e.g., "I try to control what my athletes do during their free time"). Coaches were asked to rate the extent to which they agreed with each of the statements for their coaching practices over the last month, on a scale ranging from 1 (strongly disagree) to 7 (strongly agree). Stebbings et al. (2011) similarly adapted the CCBS and reported acceptable factorial validity and internal consistency.

Social Desirability. A short form of the Marlowe-Crowne Social Desirability Scale (Strahan \& Gerbasi, 1972) was administered to assess participants' tendency to respond to questions in a socially desirable manner. Coaches were required to rate 10 items as either true or false. A socially desirable response carried a weighting of 1 , with a nonsocially desirable answer scoring 0 . The scores were then summed to produce a social desirability score for each participant. Reynolds (1982) demonstrated acceptable validity of the scale. 


\section{Results}

\section{Preliminary Analyses}

There were no missing data, as the online questionnaire program automatically prompted participants to complete a missed item. The univariate skewness values of the study variables ranged from -.08 to 1.37 , and the univariate kurtosis values ranged from .10 to 5.02, suggesting that all variables were within acceptable ranges (e.g., skewness $<3.0$ and kurtosis $<10.0$; Kline, 2010).

Data were analyzed via structural equation modeling using EQS software (version 6.1; Bentler, 2003). A combination of fit indices were examined to evaluate the degree of model fit, including the Satorra-Bentler chi square statistic $\left(\mathrm{S}-\mathrm{B} \chi^{2}\right)$, the standardized root mean square residual (SRMR), the robust comparative fit index (CFI), and the robust root mean square error of approximation (RMSEA). $\mathrm{Hu}$ and Bentler (1999) proposed that excellent fit of a hypothesized model to the data is indicated when the primary SRMR fit index is below .08, and supplementary indices, such as the CFI and RMSEA, are close to .95 and .06 , respectively. For more complex models, such as the one in the current study, these criteria have been highlighted as harsh and restrictive (Marsh, Hau, \& Wen, 2004), and therefore CFI values of above .90, and SRMR and RMSEA values of below .08 are typically recognized as acceptable.

Before examination of the full structural model, confirmatory factor analysis (CFA) was carried out to determine the factor structure of the scales used. The scale assessing perceptions of the coaching context showed some degree of misfit to the data: $\mathrm{S}-\mathrm{B} \chi^{2}(54)=172.08, p<.001 ; \mathrm{SRMR}=.14 ; \mathrm{CFI}=.94 ; \mathrm{RMSEA}=$ $.07(90 \%$ confidence interval $[\mathrm{CI}]=.06-.08)$; however, inspection of the Lagrange multiplier (LM) modification indices suggested that the addition of a covariance pathway between opportunities for professional development and job security would reduce the level of misspecification. This pathway was added because it is plausible that a coach may feel more secure in his or her job when offered opportunities for professional development. Similarly, coaches who enjoy a sense of job security may look to strengthen or further their position by seeking out opportunities for professional development. The revised factor structure showed improved fit: S-B $\chi^{2}$ $(53)=81.11, p<.001 ; \mathrm{SRMR}=.04 ; \mathrm{CFI}=.99 ; \mathrm{RMSEA}=.04(\mathrm{CI}=.02-.05)$.

The BNSAW also demonstrated inadequate factor structure: $\mathrm{S}-\mathrm{B} \chi^{2}(51)=$ $143.99, p<.001 ; \mathrm{SRMR}=.06 ; \mathrm{CFI}=.89$; RMSEA $=.07(\mathrm{CI}=.05-.08)$. Examination of the standardized loadings and standardized residuals revealed two problematic items from the relatedness subscale ("I get along with people in my coaching role" and "I consider the people I interact with in my coaching role to be friends"); hence, these items were removed from the analysis. The revised BNSAW showed good factor structure: $\mathrm{S}-\mathrm{B} \chi^{2}(32)=69.07, p<.001$; $\mathrm{SRMR}=.04$; CFI = .94; RMSEA $=.05(\mathrm{CI}=.04-.07)$. Similarly, the CFA for psychological ill-being revealed poor factor structure: $\mathrm{S}-\mathrm{B} \chi^{2}(89)=318.49, p<.001$; $\mathrm{SRMR}=.08 ; \mathrm{CFI}=.88$; RMSEA $=.08(\mathrm{CI}=.07-.09)$. Removal of one item ("scared") from the negative affect scale led to acceptable factor structure: $\mathrm{S}-\mathrm{B} \chi^{2}(76)=204.96, p<.001 ; \mathrm{SRMR}=.07$; CFI $=.92 ; \mathrm{RMSEA}=.06(\mathrm{CI}=.05-.07)$. Variable reduction procedures of this nature are justified because the original factor structure is retained, while using only the best-performing indicators (Hofmann, 1995). 
The CFA for psychological well-being demonstrated satisfactory factor structure: $\mathrm{S}-\mathrm{B} \chi^{2}(118)=266.11, p<.001 ; \mathrm{SRMR}=.05 ; \mathrm{CFI}=.92 ; \mathrm{RMSEA}=.06(\mathrm{CI}$ $=.05-.06)$, as did the scales assessing psychological need thwarting: $\mathrm{S}-\mathrm{B} \chi^{2}(51)$ $=95.55, p<.001 ; \mathrm{SRMR}=.05 ; \mathrm{CFI}=.95 ; \mathrm{RMSEA}=.05(\mathrm{CI}=.03-.06)$, coach autonomy support: $\mathrm{S}-\mathrm{B} \chi^{2}(9)=27.44, p<.001$; $\mathrm{SRMR}=.04 ; \mathrm{CFI}=.93$; RMSEA $=.07(\mathrm{CI}=.04-.10)$, coach control: $\mathrm{S}-\mathrm{B} \chi^{2}(86)=126.90, p<.001 ; \mathrm{SRMR}=.05$; $\mathrm{CFI}=.97$; RMSEA $=.03(\mathrm{CI}=.02-.05)$, and social desirability: $\mathrm{S}-\mathrm{B} \chi^{2}(35)=65.16$, $p<.001 ; \mathrm{SRMR}=.05 ; \mathrm{CFI}=.90 ; \mathrm{RMSEA}=.05(\mathrm{CI}=.03-.06)$.

\section{Descriptive Statistics and Scale Reliabilities}

Cronbach's alpha coefficients were calculated for each subscale and are presented in Table 1. All subscales demonstrated acceptable $(\alpha \geq .66)$ reliability, except for the competence need satisfaction subscale $(\alpha=.53)$ and the excessive personal control subscale $(\alpha=.60)$. This may be attributable to the low number of items to measure the constructs (three items in each subscale; Cortina, 1993); therefore, we retained these subscales because all the observed items loaded strongly onto their corresponding latent factors (i.e., >.40; Ford, MacCallum, \& Tait, 1986). Further, these items were used to calculate average competence need satisfaction and excessive personal control scores, which were subsequently used as indicators of the psychological need satisfaction and controlling behavior latent factors, respectively. Means and standard deviations of all study variables are presented in Table 1.

\section{Table 1 Descriptive Statistics and Cronbach's Alpha Coefficients for All Variables}

\begin{tabular}{clcccc}
\hline & Variable & $\alpha$ & Range & $\boldsymbol{M}$ & SD \\
\hline 1 & Opportunities for Professional Development & .86 & $1-7$ & 4.22 & 1.52 \\
2 & Job Security & .76 & $1-7$ & 3.82 & 1.39 \\
3 & Work-life Conflict & .86 & $1-7$ & 3.30 & 1.55 \\
4 & Competence Need Satisfaction & .53 & $1-7$ & 5.61 & .92 \\
5 & Autonomy Need Satisfaction & .69 & $1-7$ & 5.62 & .95 \\
6 & Relatedness Need Satisfaction & .72 & $1-7$ & 5.67 & .89 \\
7 & Competence Need Thwarting & .80 & $1-7$ & 2.17 & 1.18 \\
8 & Autonomy Need thwarting & .76 & $1-7$ & 2.48 & 1.25 \\
9 & Relatedness Need Thwarting & .69 & $1-7$ & 2.21 & 1.07 \\
10 & Positive Affect & .87 & $1-5$ & 4.04 & .59 \\
11 & Vitality & .86 & $1-7$ & 5.43 & .93 \\
12 & Negative Affect & .82 & $1-5$ & 1.61 & .56 \\
13 & Emotional and Physical Exhaustion & .93 & $1-5$ & 1.93 & .90 \\
14 & Autonomy Supportive Behaviors & .81 & $1-7$ & 5.73 & .81 \\
15 & Controlling Use of Rewards & .73 & $1-7$ & 2.46 & 1.17 \\
16 & Negative Conditional Regard & .76 & $1-7$ & 2.29 & 1.16 \\
17 & Intimidation & .77 & $1-7$ & 1.88 & 1.06 \\
18 & Excessive Personal Control & .60 & $1-7$ & 1.77 & .90 \\
19 & Social Desirability & .66 & $0-10$ & 6.80 & 2.16 \\
\hline & & & & &
\end{tabular}


Paid coaches were marginally more autonomy supportive than voluntary coaches (paid coaches, $M=5.83, S D=.73$; voluntary coaches, $M=5.57, S D=.88 ; p<.05$ ); however, there were no significant differences between the two groups in controlling behaviors (paid coaches, $M=2.14, S D=.80$; voluntary coaches, $M=2.10, S D$ $=.83 ; p>.05$ ). Bivariate correlations among latent factors (Table 2) are provided for information only as they do not relate to the study hypotheses. Nonetheless, it is worth noting that there was no evidence of multicollinearity, as all correlations were below .70 (Tabachnick \& Fidell, 1996).

\section{A Structural Model of Antecedents of Perceived Coach Behaviors}

To maintain an acceptable ratio of participants per estimated parameter, the number of indicators in the model was reduced where applicable (Bentler \& Chou, 1987). The items measuring opportunities for professional development, job security, and work-life conflict were retained as indicators of these three latent factors. The competence, autonomy, and relatedness need satisfaction and need thwarting subscales were used as indicators of overall need satisfaction and need thwarting latent factors, respectively. The positive affect and vitality subscales were used as indicators of a psychological well-being factor, whereas the negative affect and emotional and physical exhaustion subscales were used as indicators of a psychological ill-being factor. The six items from the HCCQ were parceled to create three indicators of an autonomy support latent factor, and the four subscale mean scores of the CCBS were used as indicators of coaches' perceived controlling style. Finally, social desirability was represented by a single observed variable in the interest of model parsimony, and because it was not part of the primary study hypotheses.

The proposed model was tested using the robust maximum likelihood estimation method (Mardia's normalized estimate of multivariate kurtosis $=28.60$ ). Model indices demonstrated that the fit of the hypothesized model was marginally unsatisfactory: $\mathrm{S}-\mathrm{B} \chi^{2}(391)=853.39, p<.001$; SRMR $=.07$; CFI $=.89$; RMSEA $=.05(\mathrm{CI}=.05-.06)$. Examination of the LM modification indices suggested the addition of one direct pathway from work-life conflict directly to ill-being. This pathway was subsequently included because previous research has demonstrated similar relationships (although the mediational properties of psychological need thwarting were not tested; Major et al., 2002). With the addition of this pathway, model fit indices demonstrated an acceptable fit to the data (see Figure 1): S-B $\chi^{2}$ $(390)=811.67, p<.001 ; \mathrm{SRMR}=.07 ; \mathrm{CFI}=.90 ; \mathrm{RMSEA}=.05(\mathrm{CI}=.05-.06)$. Standardized factor loadings of the indicators in the revised structural model ranged from .41 to .90 (median loading $\beta=.72$ ). ${ }^{1,2}$

Coaches reported greater psychological need satisfaction when they perceived that opportunities for professional development existed, their job was secure, and coaching did not conflict with other roles. Conversely, coaches reported greater psychological need thwarting when opportunities for development were not perceived to exist, and when coaching conflicted with other responsibilities. The relationship between job security and psychological need thwarting was nonsignificant. As discussed above, work-life conflict was also a direct positive predictor of psychological ill-being. Coaches who perceived their psychological needs to be 


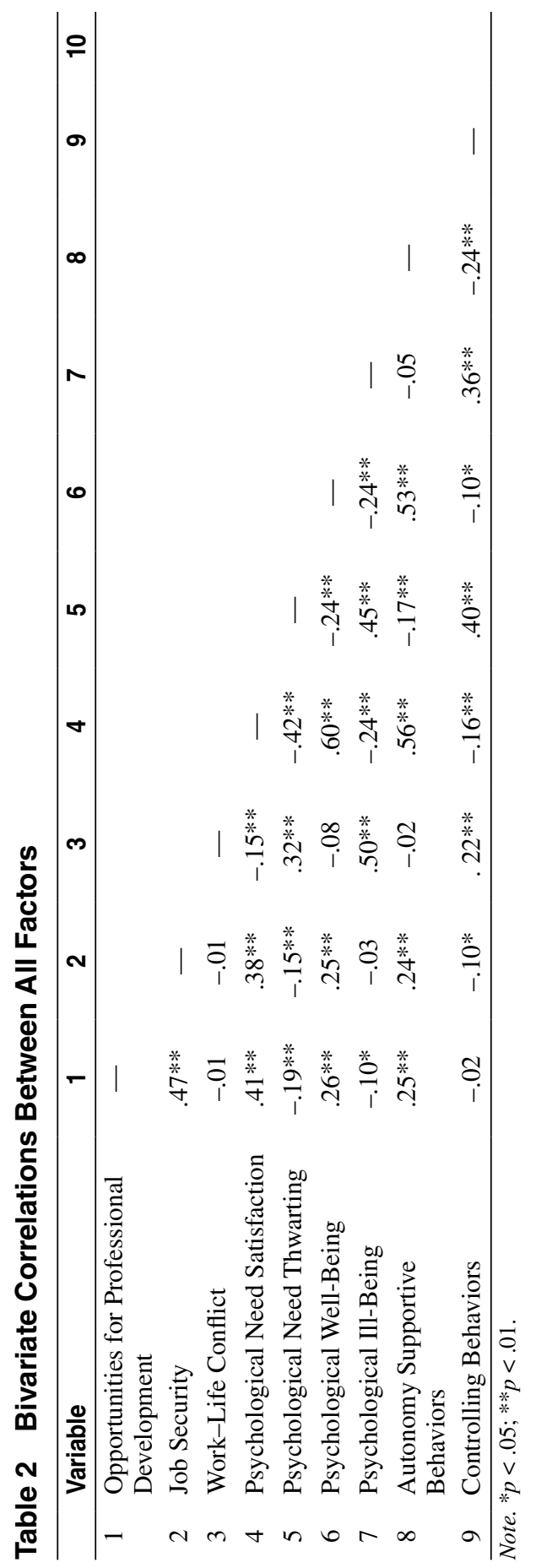




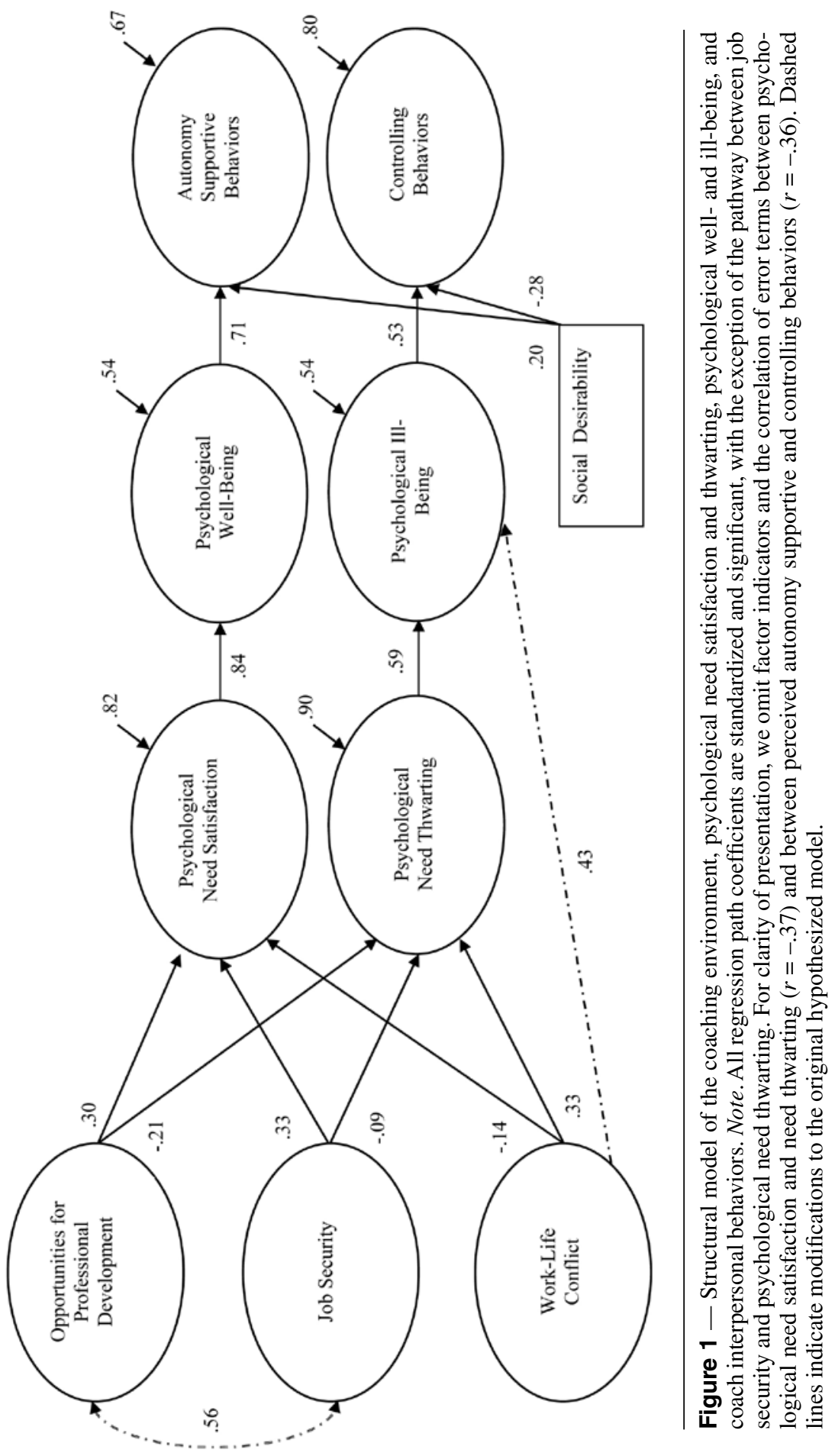


satisfied experienced enhanced psychological well-being, which, in turn, predicted coaches' perceived use of autonomy support. Similarly, coaches who perceived their psychological needs to be actively thwarted experienced greater psychological ill-being, which, in turn, predicted coaches' perceived use of control. Moderate negative associations were observed between psychological need satisfaction and need thwarting, and autonomy support and control, respectively. Lastly, social desirability demonstrated a moderate positive association with perceived autonomy support and a moderate negative association with a controlling interpersonal style.

The three coaching contextual factors accounted for $32 \%$ and $18 \%$ of the variance in coaches' need satisfaction and need thwarting, respectively. Coaches' need satisfaction accounted for $71 \%$ of the variance in psychological well-being, and need thwarting, in conjunction with work-life conflict, accounted for $71 \%$ of the variance in psychological ill-being. Finally, psychological well-being and illbeing accounted for $55 \%$ and $36 \%$ of the variance in coaches' perceived autonomy support and control, respectively.

\section{Indirect Effects}

To calculate indirect effects, bootstrapping analyses were performed. Bootstrapping techniques treat the sample as a pseudo-population from which multiple samples are drawn (Kline, 2010). To obtain the standardized indirect path coefficients and associated $95 \%$ confidence intervals (CI), parameter estimates derived from 1000 bootstrap samples were examined. When the bootstrap-generated $95 \% \mathrm{CI}$ does not contain zero, the indirect effect is deemed to be significant (Shrout \& Bolger, 2002).

Opportunities for professional development positively predicted perceived autonomy support through psychological need satisfaction and well-being $(\beta=.18$, $95 \% \mathrm{CI}=.09$ to .27 ), and negatively predicted perceived control through psychological need thwarting and ill-being $(\beta=-.06,95 \% \mathrm{CI}=-.11$ to -.02$)$. Job security positively predicted autonomy support through psychological need satisfaction and well-being $(\beta=.19,95 \% \mathrm{CI}=.10$ to .29$)$, yet did not predict perceived control $(\beta$ $=-.03,95 \% \mathrm{CI}=-.07$ to .01$)$. Work-life conflict negatively predicted perceived autonomy support through psychological need satisfaction and well-being ( $\beta=$ $-.08,95 \% \mathrm{CI}=-.14$ to -.01$)$, and positively predicted perceived control through psychological need thwarting and ill-being $(\beta=.10,95 \% \mathrm{CI}=.06$ to .16$)$.

\section{Invariance Across Competitive Levels}

Using the procedures outlined by Byrne (2006), multisample structural equation modeling was employed to examine the equality of the model across coaches working at different competitive levels (lower level = recreational and club; higher level = regional, national, and international/professional). This involved constructing separate baseline models for each group and an unconstrained baseline multigroup model, followed by three increasingly constrained models in which the factor loadings, factor variances and covariances, and structural paths were constrained to be equal. As the pathway between job security and psychological need thwarting was not significant in the full model, this was excluded from the following analyses. The baseline model for lower competitive levels revealed that the structural pathway between work-life conflict and psychological need satisfaction was nonsignificant. The multigroup baseline model showed acceptable fit to the data: $\mathrm{S}-\mathrm{B} \chi^{2}(782)=$ 
1194.73, $p<.001 ; \mathrm{SRMR}=.07 ; \mathrm{CFI}=.90 ; \mathrm{RMSEA}=.03$ (CI = .03-.04). After constraining the factor loadings to be equal, five were found to vary across groups (these loadings were associated with the work-life conflict, psychological need satisfaction, and need thwarting factors). Nonetheless, the equality constraints placed on the factor variances and covariances and structural pathways were all upheld. An equality constraint was not placed on the structural pathway between work-life conflict and psychological need satisfaction owing to its nonsignificance for lower level coaches. Unstandardized parameter coefficients (Hair, Anderson, Tatham, \& Black, 1998) were $b=-.02$, and $b=-.09$, for lower and higher level coaches, respectively. The fit of the most restrictive model was acceptable: S-B $\chi^{2}$ $(816)=1227.40, p<.001 ; \mathrm{SRMR}=.08 ; \mathrm{CFI}=.90 ; \mathrm{RMSEA}=.03(\mathrm{CI}=.03-.04)$ and the decrease in CFI value compared with the unconstrained multigroup model was less than .01, which is considered to be indicative of model invariance (Cheung \& Rensvold, 2002).

\section{Discussion}

The purpose of the current study was to test a BPNT-based model of potential antecedents of perceived coach interpersonal behavior. Controlling for socially desirable responses, the results suggest that perceived opportunities for professional development, job security, and work-life conflict may satisfy and thwart coaches' psychological needs. In turn, the results demonstrate the existence of two distinct pathways, in which psychological need satisfaction was associated with psychological well-being and an adaptive interpersonal style, whereas psychological need satisfaction was associated with psychological ill-being and a maladaptive interpersonal style. These relationships were also found to be largely invariant across competitive level. In their entirety, the current results enhance the prevailing literature by suggesting that two distinct processes may explain how the environment in which coaches operate is related to their interpersonal behavior toward their athletes. We now discuss each stage of the proposed model in turn.

\section{The Social Context and Basic Psychological Needs}

In line with previous qualitative work (Allen \& Shaw, 2009), coaches who perceived that they were provided with opportunities for professional development reported greater psychological need satisfaction, compared with coaches who did not have such opportunities. These educational opportunities may foster coaches' competence through increased knowledge and experience, increase their perceived value of coaching, and allow coaches to engage with other coaching peers. Contrastingly, opportunities for professional development demonstrated a smallto-moderate negative relationship with psychological need thwarting. If coaches are not extended professional development opportunities, they may feel isolated without the opportunity to engage with peers and that they are being prohibited from developing their coaching skills, leading to a sense of reduced competence.

Job security also emerged as a moderate positive predictor of psychological need satisfaction, an association that no other research has examined. If coaches feel secure in their role, they may attribute this to their proficiency and effectiveness as a coach. A secure position may also allow coaches the freedom to go about their 
work as they wish. Last, if coaches perceive a strong sense of job security from their employers or organizations, this may facilitate coaches' sense of belongingness within that organization. Job security, however, did not demonstrate a significant relationship with psychological need thwarting. A lack of job security may lead to low need satisfaction; however, it is plausible that only when coaches are actively made to feel insecure about their job position would overt thwarting of coaches' psychological needs occur. Indeed, evidence exists in the occupational psychology literature, in which job insecurity has been cross-sectionally and longitudinally associated with indices of poor psychological health (see Sverke, Hellgren, \& Näswall, 2006, for a review). Future research is warranted to clarify the definitions of job security versus insecurity within coaching, and assess their differential effects on psychological need satisfaction and thwarting.

Within the current study, evidence was found for a direct relationship between work-life conflict and psychological ill-being, which is consistent with previous research in the organizational domain (e.g., Major et al., 2002). Yet in accordance with the work of Van den Broeck and colleagues (2008), our findings also highlight the mediating role of basic psychological needs, as coaches operating at high competitive levels (i.e., regional level and above) who experience conflict between coaching and other life roles are likely to experience low satisfaction and high overt frustration of their psychological needs. For example, if coaches experience conflicting demands for their time and energy, they may feel as if they cannot function effectively in their coaching roles, and that their coaching practices are incompatible with other elements of their sense of self. Conflicting demands may also impact negatively upon coaches' relationships with their athletes, employers, and organizations. The relationship between work-life conflict and psychological need satisfaction, however, was nonsignificant for coaches operating at the recreational and club competitive levels. The majority of coaches working at the lower competitive levels reported coaching for fewer than $10 \mathrm{hr}$ per week, suggesting that coaching may not be a primary responsibility for many of them. It is possible that work-life conflict may not be a salient issue for these coaches.

The present study represents the first quantitative insight into how the social context can satisfy or thwart coaches' basic psychological needs. As a result, these findings offer several implications for sports organizations and practitioners to create a more adaptive working environment for coaches. Employers should aim to work alongside coaches in facilitating a sense of job security, to provide opportunities for further education and training, and to limit conflict between their coaching role and other responsibilities. For example, sporting bodies and coaches could discuss the future plans of the organization, and how the coach's role remains relevant within those plans. Formal educational pathways could be created that allow coaches to plan their coaching development and financial assistance could be made available for the coaches to partake in these training opportunities. Organizations could look to offer childcare facilities, provide opportunities for families to attend tournaments alongside the coach (Shaw \& Allen, 2009), and potentially look to increase flexibility with regards to working days and number of working hours. Finally, organizations could also create coaching partnerships in which two or more coaches share the responsibilities of preparing an athlete or team for competition, thus allowing coaches to negotiate which duties each will perform, at times which are convenient for each coach. 


\section{Basic Psychological Needs and Psychological Well- and III-Being}

Aligned with BPNT and previous research in the sport domain (e.g., Stebbings et al., 2011), results of the current study indicate that psychological need satisfaction was a strong predictor of psychological well-being, as indexed by positive affect and subjective vitality. This suggests that satisfying coaches' needs for competence, autonomy, and relatedness in their coaching role may allow coaches to psychologically thrive within that role. Contrastingly, the manifestation of psychological ill-being was predicted by the experience of psychological need thwarting, which is also in accordance with previous research (Bartholomew, Ntoumanis, Ryan, Bosch, et al., 2011). This suggests that a coach may experience heightened negative affect and emotional and physical exhaustion if they perceive the satisfaction of their psychological needs to be actively obstructed. Such findings provide support for Bartholomew and colleagues' supposition for the independence of psychological need thwarting and need satisfaction. It is important, therefore, that social agents (e.g., head coaches, performance directors, club managers, sport psychologists) aim to explicitly facilitate coaches' psychological needs while concurrently minimizing exposure to need thwarting environmental cues, particularly through the social-contextual factors outlined in the current study.

\section{Psychological Well- and III-Being and Interpersonal Behavior}

In line with Stebbings et al. (2011), results from the current study indicate that coaches' psychological well-being was a strong positive predictor of their perceived autonomy support toward their athletes. Therefore, a coach who possesses sufficient positive emotions and internal energy is likely to offer their athletes opportunities for input, decision making, taking responsibility, and to acknowledge their athletes' feelings, ideas, and opinions regarding training sessions and competitions. Such autonomy supportive strategies have been consistently shown to facilitate adaptive athlete consequences, such as self-determined motivation and enhanced psychological well-being (see Amorose, 2007). Stebbings et al. also demonstrated that coaches' psychological well-being was a negative predictor of perceived controlling behaviors; however, only $16 \%$ of the variance in controlling behaviors was accounted for. We build on this proposal by reporting that coaches' psychological ill-being was a stronger predictor of their perceived controlling behaviors toward their athletes-a relationship that no previous research has examined. Moreover, by including ill-being in the current study, a much greater percentage of variance in controlling behaviors was accounted for (36\%). If coaches experience psychological ill-being in their coaching roles, their depleted internal energy and negative emotions may lead them to become more critical, directive, and punitive toward their athletes than their psychologically healthy counterparts. In view of these findings, the current study contributes to the existing literature by suggesting that the two SDT-based interpersonal styles may have distinct antecedents, and both psychological well- and ill-being should be considered when predicting interpersonal behavior. 


\section{Indirect Effects}

As well as the direct effects discussed above, a number of significant indirect effects also emerged that provided evidence, albeit cross-sectional, for the implied processes within the conceptual model. Specifically, when coaches operate in a favorable social environment that is supportive of their basic psychological needs, an adaptive process of improved psychological health and greater perceived autonomy support may ensue. Contrastingly, when the social environment serves to undermine coaches' psychological needs, this may result in a maladaptive process of diminished psychological functioning and greater perceived controlling interpersonal behavior. These findings advance the existing literature by suggesting that creating an optimal working environment for coaches may indirectly help to create an adaptive (autonomy supportive, noncontrolling) environment for their athletes, by allowing coaches to psychologically flourish.

\section{Limitations and Future Directions}

First, the present work was cross-sectional in nature; therefore, cross-lagged longitudinal and experimental designs are warranted to clarify the direction of the processes proposed in this study. Nonetheless, our cross-sectional model was constructed from a strong theoretical and empirical research base. Second, the relationships between the "positive" factors (i.e., need satisfaction, well-being, and autonomy support), and the "negative" factors (i.e., need thwarting, ill-being, and control) may have been susceptible to shared method variance. Third, the data were based upon selfreport instruments; hence, the measurement of perceived interpersonal behaviors, in particular, may not be an accurate reflection of how coaches actually behave. Although the inclusion of a social desirability measure may have conciliated any potential bias, independent observations of coach behavior or athletes' ratings of coach behavior would complement coaches' own perceptions.

The present model can also be extended from a theoretical and practical perspective. For example, the model can be extended to incorporate other aspects of coaches' environment, such as managing multiple roles (e.g., coaching, management, administration), functioning in an isolated role, and experiencing the lack of a support system (Olusoga et al., 2009). From an applied perspective, investigation of these social-contextual factors would add to our understanding of how coaches experience their working environment and highlight elements of the context on which sporting organizations and sports psychology practitioners could intervene to create the most optimal environment for coaches. Finally, psychological need satisfaction and need thwarting were included in the present model as composite latent factors. Future research to delineate the separate effects of social-contextual factors on each psychological need would be insightful, thereby allowing practitioners to focus on enhancing any specific psychological need in which coaches are experiencing dissatisfaction or overt thwarting. In a similar fashion, future work could examine the relative contributions of the various well-/ill-being indicators on interpersonal behaviors. For instance, the energy-related indicators of welland ill-being may be stronger predictors of interpersonal style, compared with the affective indicators. Moreover, in the current study, provision of autonomy support and control were operationalized as relatively independent constructs; however, 
research in the parenting domain also exists to suggest that autonomy support and control represent opposite ends of a continuum (e.g., Soenens et al., 2009). Future research is required, therefore, to more explicitly examine the relationship between coach autonomy support and control, and whether this relationship may differ as a function of the level at which the behaviors are studied (i.e., domain or situation specific), or as a function of the information source (i.e., athlete perceptions, coach perceptions, or researchers' observed perceptions of coach behavior).

\section{Conclusions}

The current research represents the first attempt to determine how elements of the coaching environment influence psychological need satisfaction and thwarting in coaching. We also extend the extant literature by proposing two distinct mechanisms that explain how the coaching context influences coaches' perceived interpersonal style. That is, psychological well-being was more strongly predictive of an autonomy supportive style, whereas psychological ill-being was more strongly associated with a controlling style. In its entirety, the current model suggests that creating an optimal working environment for coaches, in which they can enjoy a sense of job security, opportunities for professional development, and a stable work-life balance, may allow coaches to psychologically flourish. In addition, this adaptive working environment may benefit athletes in terms of the adaptive (autonomy supportive, noncontrolling) interpersonal environment that coaches will subsequently create.

\section{Notes}

1. At the request of a reviewer, we also tested a social contextual factors $\rightarrow$ psychological need satisfaction/thwarting $\rightarrow$ autonomy support/control $\rightarrow$ psychological well-/ill-being sequence. This model did not fit the data well: $\mathrm{S}-\mathrm{B} \chi^{2}(390)=884.15, p<.001 ; \mathrm{SRMR}=.07 ; \mathrm{CFI}=.88$; RMSEA $=.06(\mathrm{CI}=.05-.06)$, and modifications suggested by the Lagrange multiplier test (i.e., the addition of direct pathways from psychological need satisfaction/thwarting $\rightarrow$ well-/ill-being) mirrored our hypothesized model.

2. One reviewer suggested that we test the direct relationships between need satisfaction and autonomy support, and between need thwarting and control. Both were significant ( $\beta=.39$ and .23 , respectively); however, the inclusion of these direct effects did not significantly improve model fit over the current model $(\Delta \mathrm{CFI}<.01$; Cheung \& Rensvold, 2002). Moreover, the paths between well-being and autonomy support, and ill-being and control, still remained significant even with these direct paths estimated. A second reviewer suggested that we test the direct relationships between the three contextual factors and the well-/ill-being and autonomy support/ control factors. Only four out of these 11 additional direct effects were significant (job security $\rightarrow$ ill-being, job security $\rightarrow$ controlling behaviors, work-life conflict $\rightarrow$ autonomy supportive behaviors, and work-life conflict $\rightarrow$ controlling behaviors), and the inclusion of these direct effects did not improve model fit.

\section{References}

Allen, J.B., \& Shaw, S. (2009). Women coaches' perceptions of their sport organizations' social environment: Supporting coaches' psychological needs? The Sport Psychologist, 23, 346-366. Retrieved from http://journals.humankinetics.com/tsp 
Amorose, A.J. (2007). Coaching effectiveness. In M.S. Hagger \& N.L.D. Chatzisarantis (Eds.), Intrinsic motivation and self-determination in exercise and sport (pp. 209-227). Leeds: Human Kinetics.

Bakker, A.B., \& Demerouti, E. (2007). The job demands-resources model: State of the art. Journal of Managerial Psychology, 22, 309-328. doi:10.1108/02683940710733115

Bartholomew, K.J., Ntoumanis, N., Ryan, R.M., Bosch, J.A., \& Thøgersen-Ntoumani, C. (2011). Self-determination theory and diminished functioning: The role of interpersonal control and psychological need thwarting. Personality and Social Psychology Bulletin, 37, 1459-1473. PubMed doi:10.1177/0146167211413125

Bartholomew, K.J., Ntoumanis, N., Ryan, R.M., \& Thøgersen-Ntoumani, C. (2011). Psychological need thwarting in the sport context: Assessing the darker side of athletic experience. Journal of Sport \& Exercise Psychology, 33, 75-102. Retrieved from http:// journals.humankinetics.com/jsep PubMed

Bartholomew, K.J., Ntoumanis, N., \& Thøgersen-Ntoumani, C. (2010). The controlling interpersonal style in a coaching context: Development and initial validation of a psychometric scale. Journal of Sport \& Exercise Psychology, 32, 193-216. Retrieved from http://journals.humankinetics.com/jsep PubMed

Bentler, P.M. (2003). EQS 6.1 for Windows. Encino, CA: Multivariate Software. [Computer software].

Bentler, P.M., \& Chou, C.P. (1987). Practical issues in structural modeling. Sociological Methods \& Research, 16, 78-117. doi:10.1177/0049124187016001004

Byrne, B.M. (2006). Structural equation modeling with EQS: Basic concepts, applications, and programming (2nd ed.). Mahwah, NJ: Lawrence Erlbaum Associates.

Cheung, G.W., \& Rensvold, R.B. (2002). Evaluating goodness-of-fit indexes for testing measurement invariance. Structural Equation Modeling, 9, 233-255. doi:10.1207/ S15328007SEM0902 5

Chelladurai, P., \& Ogasawara, E. (2003). Satisfaction and commitment of American and Japanese collegiate coaches. Journal of Sport Management, 17, 62-73. Retrieved from http://journals.humankinetics.com/jsm

Cortina, J.M. (1993). What is coefficient alpha? An examination of theory and applications. The Journal of Applied Psychology, 78, 91-104. doi:10.1037/0021-9010.78.1.98

Deci, E.L., \& Ryan, R.M. (2000). The "what" and "why" of goal pursuits: Human needs and the self-determination of behavior. Psychological Inquiry, 11, 227-268. doi:10.1207/ S15327965PLI1104_01

Deci, E.L., Ryan, R.M., Gagné, M., Leone, D.R., Usunov, J., \& Kornazheva, B.P. (2001). Need satisfaction, motivation, and well-being in the work organizations of a former Eastern Bloc country: A cross-cultural study of self-determination. Personality and Social Psychology Bulletin, 27, 930-942. doi:10.1177/0146167201278002

Ford, J., MacCallum, R., \& Tait, M. (1986). The application of factor analysis in psychology: A critical review and analysis. Personnel Psychology, 39, 291-314. doi:10.1111/j.1744-6570.1986.tb00583.x

Forgas, J.P. (2002). Feeling and doing: Affective influences on interpersonal behavior. Psychological Inquiry, 13, 1-28. doi:10.1207/S15327965PLI1301_01

Gagné, M., Ryan, R.M., \& Bargmann, K. (2003). Autonomy support and need satisfaction in the motivation and well-being of gymnasts. Journal of Applied Sport Psychology, 15, 372-390. doi:10.1080/714044203

Hair, J.E., Anderson, R.E., Tatham, R.L., \& Black, W.C. (1998). Multivariate data analysis (5th ed.). Upper Saddle River, NJ: Prentice-Hall.

Hofmann, R. (1995). Establish factor validity using variable reduction in confirmatory factor analysis. Educational and Psychological Measurement, 55, 572-582. doi:10.1177/0013164495055004005

$\mathrm{Hu}, \mathrm{L} .$, \& Bentler, P.M. (1999). Cut-off criteria for fit indexes in covariance structure analysis: Conventional criteria versus new alternatives. Structural Equation Modeling, 6, 1-55. doi:10.1080/10705519909540118 
Kline, R.B. (2010). Principles and practice of structural equation modeling (3rd ed.). New York: Guilford Press.

Klusmann, U., Kunter, M., Trautwein, U., Lüdtke, O., \& Baumert, J. (2008). Teachers' occupational well-being and quality of instruction: The important role of self-regulatory patterns. Journal of Educational Psychology, 100, 702-715. doi:10.1037/00220663.100.3.702

Mageau, G.A., \& Vallerand, R.J. (2003). The coach-athlete relationship: A motivational model. Journal of Sports Sciences, 21, 883-904. PubMed doi:10.1080/0264041031000140374

Maslach, C., \& Leiter, M.P. (1997). The truth about burnout: How organizations cause personal stress and what to do about it. San Francisco, CA: Jossey-Bass.

Major, V.S., Klein, K.J., \& Ehrhart, M.G. (2002). Work time, work interference with family, and psychological distress. The Journal of Applied Psychology, 87, 427-436. PubMed doi:10.1037/0021-9010.87.3.427

Marsh, H.W., Hau, K., \& Wen, Z. (2004). In search of golden rules: Comment on hypothesistesting approaches to setting cutoff values for fit indexes and dangers in overgeneralizing Hu and Bentler's (1999) findings. Structural Equation Modeling, 11, 320-341. doi:10.1207/s15328007sem1103_2

Netemeyer, R.G., Boles, J.S., \& McMurrian, R. (1996). Development and validation of workfamily conflict and family-work conflict scales. The Journal of Applied Psychology, 81, 400-410. doi:10.1037/0021-9010.81.4.400

Ntoumanis, N. (2005). A prospective study of participation in optional school physical education using a self-determination theory perspective. Journal of Educational Psychology, 97, 444-453. doi:10.1037/0022-0663.97.3.444

Olusoga, P., Butt, J., Hays, K., \& Maynard, I. (2009). Stress in elite sports coaching: Identifying stressors. Journal of Applied Sport Psychology, 21, 442-459. doi:10.1080/10413200903222921

Pelletier, L.G., Fortier, M.S., Vallerand, R.J., \& Brière, N.M. (2001). Associations among perceived autonomy support, forms of self-regulation, and persistence: A prospective study. Motivation and Emotion, 25, 279-306. doi:10.1023/A:1014805132406

Probst, T.M. (2003). Development and validation of the Job Security Index and the Job Security Satisfaction scale: A classical test theory and IRT approach. Journal of Occupational and Organizational Psychology, 76, 451-467. doi:10.1348/096317903322591587

Quested, E., \& Duda, J.L. (2010). Exploring the social-environmental determinants of well- and ill-being in dancers: A test of basic needs theory. Journal of Sport \& Exercise Psychology, 32, 39-60. Retrieved from http://journals.humankinetics.com/jsep PubMed

Raedeke, T.D., \& Smith, A.L. (2001). Development and preliminary validation of an athlete burnout measure. Journal of Sport \& Exercise Psychology, 23, 281-306 Retrieved from http://journals.humankinetics.com/jsep

Reynolds, W.M. (1982). Development of reliable and valid short forms of the MarloweCrowne social desirability scale. Journal of Clinical Psychology, 38, 119-125. doi:10.1002/1097-4679(198201)38:1<119::AID-JCLP2270380118>3.0.CO;2-I

Ryan, R.M., \& Frederick, C.M. (1997). On energy, personality and health: Subjective vitality as a dynamic reflection of well-being. Journal of Personality, 65, 529-565. PubMed doi:10.1111/j.1467-6494.1997.tb00326.x

Schaufeli, W.B., \& Bakker, A.B. (2004). Job demands, job resources, and their relationship with burnout and engagement: A multisample study. Journal of Organizational Behavior, 25, 293-315. doi:10.1002/job.248

Shaw, S., \& Allen, J.B. (2009). The experiences of high performance women coaches: A case study of two regional sport organisations. Sport Management Review, 12, 217-228. doi:10.1016/j.smr.2009.03.005

Shirom, A., Nirel, N., \& Vinokur, A.D. (2006). Overload, autonomy, and burnout as predictors of physicians' quality of care. Journal of Occupational Health Psychology, 11, 328-342. PubMed doi:10.1037/1076-8998.11.4.328 
Shrout, P.E., \& Bolger, N. (2002). Mediation in experimental and nonexperimental studies: New procedures and recommendations. Psychological Methods, 7, 422-445. PubMed doi:10.1037/1082-989X.7.4.422

Soenens, B., Sierens, E., Vansteenkiste, M., Dochy, F., \& Goossens, L. (2012). Psychologically controlling teaching: Examining outcomes, antecedents, and mediators. Journal of Educational Psychology, 104, 108-120. doi:10.1037/a0025742.

Soenens, B., Vansteenkiste, M., \& Sierens, E. (2009). How are parental psychological control and autonomy-support related? A cluster-analytic approach. Journal of Marriage and the Family, 71, 187-202. doi:10.1111/j.1741-3737.2008.00589.x

Stebbings, J., Taylor, I.M., \& Spray, C.M. (2011). Antecedents of perceived coach autonomy supportive and controlling behaviors: Coach psychological need satisfaction and wellbeing. Journal of Sport \& Exercise Psychology, 33, 255-272. Retrieved from http:// journals.humankinetics.com/jsep PubMed

Strahan, R., \& Gerbasi, K.C. (1972). Short, homogeneous versions of the Marlowe-Crowne social desirability scale. Journal of Clinical Psychology, 28, 191-193. doi:10.1002/10974679(197204)28:2<191::AID-JCLP2270280220>3.0.CO;2-G

Sverke, M., Hellgren, J., \& Näswall, K. (2006). Job insecurity: A literature review. In B. Badura, H. Schellschmidt, \& C. Vetter (Eds.), Absenteeism report 2005: Job insecurity and well-being (pp. 59-92). Berlin: Springer-Verlag.

Tabachnick, B.G., \& Fidell, L.S. (1996). Using multivariate statistics (3rd ed.). New York: Harper Collins.

Taylor, I.M., Ntoumanis, N., \& Standage, M. (2008). A self-determination theory approach to understanding the antecedents of teachers' motivational strategies in physical education. Journal of Sport \& Exercise Psychology, 30, 75-94. Retrieved from http://journals .humankinetics.com/jsep PubMed

Van den Broeck, A., Vansteenkiste, M., De Witte, H., \& Lens, W. (2008). Explaining the relationships between job characteristics, burnout, and engagement: The role of basic psychological need satisfaction. Work and Stress, 22, 277-294. doi:10.1080/02678370802393672

Watson, D., Tellegen, A., \& Clark, L. (1988). Development and validation of brief measures of positive. PubMed doi:10.1037/0022-3514.54.6.1063

Williams, G.C., Grow, V.M., Freedman, Z.R., Ryan, R.M., \& Deci, E.L. (1996). Motivational predictors of weight loss and weight-loss maintenance. Journal of Personality and Social Psychology, 70, 115-126. PubMed doi:10.1037/0022-3514.70.1.115

Manuscript submitted: August 16, 2011

Revision accepted: April 1, 2012 